\title{
Jogos e brincadeiras: modificações entre gerações
}

\author{
Games and plays: modifications between generations \\ Juegos y chistes: modificaciones entre generaciones \\ TALILA SCHIMITH ${ }^{1}$; ANDRESA de SOUZA UGAYA ${ }^{2}$ \\ Secretaria da EducaÇão do Estado de São Paulo, SEe-SP, Catanduva-SP, Brasil \\ Universidade Estadual Paulista “Júlio de Mesquita Filho”, UNESP, BaURu-SP, Brasil
}

\section{RESUMO}

Este artigo é parte da dissertação de mestrado de uma pesquisa qualitativa que pretendeu refletir sobre como os jogos e brincadeiras se inserem em tempos-espaços, na construção social e cultural de diferentes gerações de estudantes dos sextos anos de uma escola estadual do município de Catanduva. Para o levantamento dos dados, utilizamos o questionário de autoaplicação com perguntas distintas para os alunos e para as famílias, bem como o diário de campo e as produções realizadas pelos educandos (desenhos, redações e vídeos). Cada família elencou uma brincadeira que a representasse e estas foram vivenciadas pelas crianças. A análise de dados aconteceu por meio de categorias dos conteúdos e os resultados nos mostram a contribuição que os diferentes contextos proporcionam para as trocas de experiências entre as gerações.

Palavras-chave: Jogos. Brincadeiras. Educação Física Escolar.

\begin{abstract}
This article is part of the master's dissertation of a qualitative research that intended to reflect on how games and plays are inserted in time-spaces, in the social and cultural construction of different generations of students of the sixth years of a state school in the city of Catanduva. To collect the data, we used the self-application questionnaire with different questions for students and families, as well as the field diary and the productions made by the students (drawings, essays and videos). Each family listed a game that represented it and these were experienced by the children. Data analysis took place through content categories and the results show us the contribution that different contexts provide for the exchange of experiences between generations.
\end{abstract}

Keywords: Games. Plays. School Physical Education.

\section{RESUMEN}

Este artículo es parte de la disertación de maestría de una investigación cualitativa que tuvo como objetivo reflexionar sobre cómo los juegos y los chistes se insertan en los espacios de tiempo, en la construcción social y cultural de diferentes generaciones de estudiantes de sexto año de una escuela estatal en el municipio de Catanduva Para recopilar los datos, utilizamos el cuestionario de autoaplicación con diferentes preguntas para estudiantes y familias, así como el diario de campo y las producciones realizadas por los estudiantes (dibujos, ensayos y videos). Cada familia enumeró un juego que lo representaba y estos fueron experimentados por los niños. El análisis de datos se realizó a través de categorías de contenido y los resultados nos muestran la contribución que los diferentes contextos proporcionan para el intercambio de experiencias entre generaciones.

Palabras clave: Juegos. Chistes. Educación Física Escolar.

\footnotetext{
${ }^{1}$ Mestre em Educação Física (PROEF/UNESP Bauru). Professora de Educação Física da SEE-SP Catanduva. Email: lilaschimith@hotmail.com. ORCID: https://orcid.org/0000-0002-9504-1854.

${ }^{2}$ Professora do Departamento de Educação Física da UNESP Bauru e do Programa de Mestrado Profissional em Educação Física em Rede Nacional (PROEF/UNESP Bauru). E-mail: ugaya@fc.unesp.br. ORCID: http://orcid.org/0000-0001-9864-5971.
} 


\section{INTRODUÇÃO}

Existe uma dificuldade para conceituar a palavra jogo, pois ele pode ser entendido a partir de várias significações, dependendo do contexto e do sentido que cada sociedade lhe atribui. Assim, certo jogo pode ser considerado como tal em uma cultura e em outra, não (KISHIMOTO, 1995).

Brougère (2010) afirma que, desde o nascimento, a criança está inserida num contexto social e os seus comportamentos estão impregnados de cultura. Desta maneira, "[...] não existe na criança uma brincadeira natural. A brincadeira é um processo de relações interindividuais, portanto de cultura" (BROUGÈRE, 2010, p. 97).

Corroborando, Kishimoto (1998) disserta que o brincar não é intrínseco ao indivíduo, mas uma atividade com significação social que, assim como as outras, necessita de aprendizagem. Para os autores, a criança ao brincar não se preocupa com os resultados já que suas ações são impulsionadas pelo prazer e pela motivação. A conduta lúdica contribui para a exploração e a flexibilidade do ser que brinca.

Ariés (1986, p. 124) afirma que "[...] muitos dos componentes lúdicos utilizados no séc. XVII sobrevivem através dos tempos". Atualmente, os jogos e as brincadeiras se fazem presentes nas sociedades, pois, foram e são transmitidos a partir do contexto familiar. Eles podem aparecer de outra maneira ou com outra denominação, mas o conteúdo e a forma como o fazem é praticamente a mesma. Nesse sentido, "[...] muitas brincadeiras preservam sua estrutura inicial, outras modificam-se, recebendo novos conteúdos" (KISHIMOTO, 2011, p. 43).

Nesse sentido, Santos (2013) salienta que o brincar e as brincadeiras fazem parte da vida das crianças e estas são passadas de uma geração para a outra. Para a autora, o brincar também "[...] é aprendido no cotidiano de suas vidas, na convivência com seus pares nas ruas, parque, escolas, de forma em que ao brincar e se socializar com outras crianças estas produzem suas culturas infantis" (p. 79).

Para Pontes e Magalhães (2003, p. 122) "[...] é dentro do grupo que ocorrem tanto a uniformidade e a constância como as variações e as novidades" e essa troca acontece através das interações entre as pessoas do grupo. Os autores ainda complementam que a cultura da brincadeira só acontece em um conjunto de sujeitos, que se identificam e têm um modo próprio de organização. Com isso, é possível que a brincadeira tradicional seja mantida e repassada.

É por meio do brincar que a aprendizagem das crianças é facilitada, uma vez que são postas em jogo sua autonomia, identidade e, principalmente, sua criatividade. Winnicott (1975,) esclarece que "[...] é no brincar, e talvez apenas no brincar, que a criança ou o adulto fluem sua liberdade de criação e podem utilizar sua personalidade integral e é somente sendo criativo que o indivíduo descobre o eu" (p. 79).

Contribuindo para essa discussão Leite e Medeiros (2014, p. 146) afirmam que "[...] ao brincar, as crianças aprendem e fazem experiências de convivência. Negociam regras e papéis, lidam com seus desejos e frustrações, aprendem a cuidar do próximo, interagem com diferentes idades".

Carvalho et al. (2003) afirmam que "[...] todas as crianças brincam, brincam de acordo com seu meio, facilidades, condições, oportunidades - e brincam, principalmente, pelo grande prazer de brincar" (p. 185). O brincar se faz presente no desenvolvimento do ser humano e, por isso, todas as características e acontecimentos de uma sociedade influenciam nas atividades lúdicas e marcam os jogos e brincadeiras.

[...] adultos e crianças brincam quando se entregam a um momento presente, em plenitude, com inteireza. Brincam, simplesmente, pelo prazer e vontade de brincar. É um momento de entrega e liberdade. Não há um objetivo ou 
intencionalidade a ser alcançado. Há a possibilidade de fazer aquilo ou não, de escolher com quem irá brincar, onde e quando isso acontecerá. Ficamos envolvidos com a brincadeira por simples fruição, pelo prazer de desafiar a nós mesmos, pelo fato de nos relacionarmos com outras pessoas ou objetos. Temos a liberdade de interrompê-la a qualquer momento. Podemos mudar as regras de um jogo, se quisermos. A espontaneidade é parte intrínseca ninguém brinca verdadeiramente, se for obrigado a fazer isso (LEITE; MEDEIROS, 2014, p. 145-146).

Para as autoras, o brincar é conviver e fazer relações tanto com outras pessoas como consigo mesmo e com objetos. É no brincar que a criança explora e conhece o mundo e interage com tudo que está a sua volta. "Inserida em uma cultura, observa, fica curiosa, faz experimentações e vai construindo conhecimento em suas relações" (LEITE; MEDEIROS, 2014, p. 147). Logo, é durante o brincar que as crianças assimilam os elementos da cultura, agem sobre ela, a recriam, bem como, inventam coisas novas.

Kishimoto (1998) reforça a ideia de que o jogo, como qualquer atividade humana, se desenvolve e tem sentido no contexto das interações e da cultura. Portanto, as crianças estão sempre criando novos significados, aprendendo com a cultura em que está inserida e também produzindo cultura e construindo significados. Assim sendo, "[...] as crianças são produtoras de cultura!" (BRASIL, 2005, p. 22).

Em outras palavras, Corsaro (2005) apud Santos (2013) afirma que o desenvolvimento das crianças não é individual e, sim, coletivo, ou melhor dizendo, um processo cultural que acontece através das relações existentes das crianças com os demais. Para ele, a criança é um ser capaz de produzir a própria cultura e não apenas incorporar aquela advinda do adulto. A criança recebe a cultura oferecida a ela pelo adulto, apropria-se dela, modifica-a e produz uma cultura própria.

No entanto, vale ressaltar que os comportamentos lúdicos apresentam significados distintos em cada cultura. "Se para a criança europeia a boneca significa um brinquedo, um objeto, suporte de brincadeira, para certas populações indígenas tem o sentido de símbolo religioso" (KISHIMOTO, 1993, p. 8). Para a autora, um mesmo comportamento pode ser visto como jogo ou não-jogo.

Se para um observador externo a ação da criança indígena que se diverte atirando com arco e flecha em pequenos animais é uma brincadeira, para a comunidade indígena nada mais é que uma forma de preparo para a arte de caça necessária à subsistência da tribo. Assim, atirar com arco e flecha, para uns, é jogo, para outros, é preparo profissional. Uma mesma conduta pode ser jogo ou não-jogo em diferentes culturas, dependendo do significado a ela atribuído. Por tais razões fica difícil elaborar uma definição de jogo que englobe a multiplicidade de suas manifestações concretas. Todos os jogos possuem peculiaridades que os aproximam ou distanciam (KISHIMOTO, 2011, p. 17-18).

Partindo dessa conjectura, sabe-se que é através dessa convivência e interação com os demais que ocorrem o processo de socialização e aprendizagem das crianças. No entanto, é na família e na escola que ocorrem os primeiros contatos das crianças com o processo de formação das mesmas.

Para Hirsh-Pasek (2006), atualmente, alguns responsáveis têm a falsa crença de que o brincar não é importante e que se constitui, inclusive, uma perda de tempo. Nesse pensamento, englobam erroneamente a ideia de que as crianças apenas brincam e não estão aprendendo nada. 
Segundo Pereira (2015), muitas famílias consideram os estudos, as tarefas de casa e muitos outros afazeres mais importantes que o brincar e, por isso, oferecem uma agenda lotada aos pequenos, o que gera tensão e estresse exacerbados e prematuros. A autora complementa dizendo que, ao buscar meios de tornarem as crianças responsáveis, atenciosas, equilibradas, as famílias se esquecem que o brincar pode ser justamente uma ferramenta que também possibilita o desenvolvimento dessas qualidades.

Corroborando com a autora, Hirsh-Pasek (2006, p. 235) afirma que “[...] os momentos de brincadeiras são, na realidade, oportunidades de aprendizagem 'disfarçadas', e que é preciso dar uma atenção especial a eles, principalmente no meio familiar, cuja interação se dá primeiramente”.

Outro quesito que acaba fazendo com que as famílias participem pouco desses momentos com seus filhos é a falta de tempo. Isso acaba prejudicando a organização do tempo das crianças e as expõem a um longo período em frente à TV, computadores e outras tecnologias digitais sem uma devida e necessária mediação. Sendo assim, elas deixam de realizar outras atividades fundamentais para um desenvolvimento desejável, como o brincar e o jogar em família (PEREIRA, 2015).

\begin{abstract}
O tempo da criança não é fácil de gerir. Essa dificuldade se agrava, quando pais ou membros da família têm dificuldades de organizar o tempo e horário de seus filhos por passarem maior tempo fora do ambiente familiar, e, quando o fazem, baseiam-se geralmente em seus princípios e modos de pensar, que nem sempre são os mais indicados (VOLPATO, 2002, p. 77).
\end{abstract}

Nessa perspectiva, Zamberlan e Biasoli-Alves (1997) alegam que o papel dos pais e mães não consiste apenas em prover os bens materiais e o sustento dos seus filhos, a educação informal e nem o preparo para a educação formal. As famílias têm o papel de dividir as tarefas, controlar as rotinas a fim de desfrutarem mais tempos com seus filhos e transmitir valores culturais de diversas naturezas.

As famílias precisam rever as atividades destinadas aos filhos. Cursos de inglês, ballet, informática, teatro, desenho, patinação e tantos outros afazeres são momentos importantes na aprendizagem das crianças, mas é através do brincar, parte integrante da cultura infantil, que se deve privilegiar e garantir esse processo (PEREIRA, 2015).

Os seres humanos são diferentes e é nessa diferença que ocorre a compreensão dos limites e possibilidades de cada indivíduo. Assim como a família, a escola também tem a incumbência de se reorganizar, redimensionando o tempo e o espaço do trabalho escolar, flexibilizar os conteúdos e, principalmente, aprender a lidar com o uno e o diverso concomitantemente (COSTA; SOUSA, 2004).

Acreditamos que o papel da escola e dos educadores não é transmitir informações, e sim, propiciar práticas pedagógicas que possibilitem elaborações que desafiem as crianças a pensarem, a escolherem quais caminhos seguir e a resolução de situaçõesproblema que surjam no cotidiano, contribuindo para a formação de futuros cidadãos críticos e conscientes de seu papel no mundo (BORDENAVE, 1994; GUIMARÃES et al., 2001; VAGO, 2009; SOUZA; LEITÃO; PRODÓCIMO, 2016).

Chicon, Sá e Fontes (2014) corroboram quando afirmam que o papel de mediador do professor é decisivo no processo. Para eles,

[...] o professor deve atuar com uma preocupação em atender às diferenças e, para cumprir esse papel, precisa agir como mediador nas relações dos alunos consigo mesmo, com os colegas e com os objetos, ajudando-os a superar as dificuldades que emergem do processo ensino-aprendizagem e orientando-os 
para que atinjam níveis de independência e autonomia (CHICON; SÁ; FONTES, 2014, p. 19).

Outro papel atribuído à equipe escolar como um todo é conscientizar as famílias de que as experiências por meio do brincar são apropriadas para o desenvolvimento das crianças. No que concerne às atividades lúdicas, a escola apresenta-se como facilitadora do processo de interação entre a comunidade escolar, as famílias e as crianças, conforme afirmação: "A escola pode servir de local facilitador para que algumas atividades lúdicas possam acontecer, permitindo a interação maior entre escola e família, ao mesmo tempo que pode favorecer uma maior proximidade entre familiares/cuidadores e crianças" (POLETTO, 2005, p. 74).

Sabemos que a diversidade cultural proporciona uma gama de oportunidades de conhecimentos acerca dos jogos e brincadeiras. Nesse sentido, a vontade de compreender como as gerações se expressam nesse aspecto, foi o ponto partida para a organização e o desenvolvimento do tema que encadeou esta pesquisa.

Destarte, o objetivo foi refletir sobre como os jogos e as brincadeiras se inserem em tempos-espaços na construção social e cultural de diferentes gerações. Para isto foi proposta uma ação didática em que os jogos e/ou as brincadeiras do contexto familiar de cada aluno fossem identificados e vivenciados com os colegas da escola.

\section{METODOLOGIA}

O método que guiou esta pesquisa, de caráter qualitativo, foi a pesquisa de campo que, segundo Gonsalves (2001), tem como pressuposto a busca pelas informações diretamente no contexto social, exigindo do pesquisador um contato mais direto com o público participante. Esse método está relacionado a um estudo empírico para conhecer determinada realidade, sendo que, o pesquisador, para levantar os dados, deve ter os instrumentos e técnicas já especificados (DOXSEY; DE RIZ, 2003).

Para analisar os dados utilizamos a análise categorial temática (GOMES, 2007) que estabelece classificações, possibilitando o agrupamento de ideias ou expressões em torno de um conceito.

A categorização tanto pode ser realizada previamente, exigindo um conhecimento sólido por parte do pesquisador para encontrar um esquema classificatório adequado do assunto a ser analisado, como pode surgir a partir da análise do material de pesquisa (GOMES, 2007, p. 88).

Gomes (2007) salienta que, para que tenhamos essa categorização em uma análise de dados em uma pesquisa qualitativa, é importante garantirmos que as categorias sejam homogêneas, isto é, que cada classe deve ser obtida a partir dos mesmos princípios utilizados para toda a categorização.

Especificamente para esta pesquisa, as categorias emergiam com o decorrer da análise dos dados que foram levantados através de três instrumentos: questionário, diário de campo e registros das crianças.

O questionário (DEL-MASSO; COTTA; SANTOS, 2018) foi o de autoaplicação tanto para os alunos quanto para os responsáveis.

O diário de campo (MINAYO, 2014) foi utilizado para registrar todas as etapas realizadas, levando em conta o contexto, as manifestações, ações, atitudes dos alunos e as reflexões acerca das aulas. No que concerne aos registros dos alunos, os mesmos 
foram: desenhos que retrataram a família, vídeos das brincadeiras escolhidas e redação relatando a experiência.

A pesquisa foi realizada em uma escola da rede estadual da Diretoria de Ensino de Catanduva-SP. O público convidado a participar foi quarenta e nove alunos de três sextos anos, com idade entre 10 a 14 anos.

Iniciamos o percurso investigativo, explicando-o aos estudantes e convidando-os a participarem e contribuírem juntamente com suas famílias. Nessa explanação, os objetivos e as etapas foram detalhadas e os educandos receberam o Termo de Consentimento Livre e Esclarecido, o Termo de Assentimento Livre e Esclarecido e o roteiro com seis questões que o responsável escolhido por eles deveria responder.

Então, os alunos levaram os termos e o questionário e tiveram o prazo estipulado de quinze dias para a devolução. Após a entrega dos documentos por trinta e três alunos, estes responderam ao questionário em sala de aula.

Para preservar as crianças e os adolescentes, estes escolheram nomes fictícios, pelos quais serão citados no decorrer do trabalho.

Cada educando teve a incumbência de escolher um responsável habitante da mesma casa e maior de idade para integrar a pesquisa e responder o questionário, escolhendo também uma brincadeira que representasse sua família. A pesquisa totalizou 66 sujeitos dentre alunos e responsáveis. A pessoa escolhida pelo aluno foi convidada a participar do estudo para sabermos como aconteciam os jogos e brincadeiras em outros tempos e gerações.

A etapa seguinte compreendeu uma roda de conversa sobre a família e sua importância e, logo após, os discentes fizeram um desenho que representou a sua concepção de família.

Feito o levantamento das brincadeiras escolhidas pelas famílias, as quais foram descritas no questionário e também enviadas por meio de vídeos no aplicativo Whatsapp, as aulas foram organizadas de modo a abarcar todos os jogos e/ou brincadeiras, sendo que, cada turma utilizou para vivenciar as brincadeiras: $6^{\circ} \mathrm{A}-\mathrm{dez}$ aulas; $6^{\circ} \mathrm{B}-\operatorname{dez}$ aulas; $6^{\circ} \mathrm{C}$ - oito aulas. Vale ressaltar que os estudantes que não apresentaram os termos, também puderam trazer um jogo ou brincadeira e participar das vivências. No entanto, os dados desses alunos não foram utilizados respeitando os procedimentos éticos da pesquisa.

Ao final, as crianças puderam escrever e relatar o que vivenciaram, os sentimentos, as dificuldades e o aprendizado que tiveram nos meses de desenvolvimento das aulas.

\section{RESULTADOS}

Com o passar do tempo e a transformação da cultura, especificamente a lúdica, houve transformações nos jogos e nas brincadeiras, mas o prazer pelo jogo e pela brincadeira deve permanecer sempre (FRIEDMANN, 1996 apud CARDOSO, 2004).

A responsável pelo aluno Paraíba lembrou-se da brincadeira prazerosa de "queimada" na sua época:

[...] a brincadeira na época era bem gostosa. Nós corríamos bastante e, às vezes, ficávamos chateados quando o coleguinha ou primo jogava a bola com muita força, mas depois ficava todo mundo numa boa, não tinha aquelas brigas como hoje tem nos campos. Era uma coisa, assim, gostosa. A gente se divertia bastante (Pessoa escolhida do Paraíba). 
Revivendo os jogos e as brincadeiras, as pessoas escolhidas pelos alunos trouxeram à tona em quais lugares costumavam brincar quando crianças, como podemos verificar na tabela 1 :

Tabela 1: Lugares que os responsáveis brincavam quando criança.

\begin{tabular}{l|c}
\hline Lugar & Total \\
\hline Rua & 26 \\
Casa & 21 \\
Escola & 20 \\
Casa de amigos & 16 \\
Espaços públicos (campos, praças etc.) & 11 \\
Outros & 04 \\
\hline
\end{tabular}

Fonte: Elaborada pelas autoras.

Ao analisarmos os espaços que os responsáveis brincavam, temos a rua como o mais citado, seguido por casa, escolas e casa de amigos. O item "outros" que apareceu quatro vezes é compreendido por casa de primos, sítio, casas abandonadas e piscina.

Do mesmo modo que algumas brincadeiras modificaram, os espaços que as crianças utilizam para brincar também foram alterados. Se antes as ruas eram tomadas por jogos e brincadeiras tradicionais, atualmente estas acontecem, comumente, dentro da própria casa com a utilização, na maioria das vezes, de celulares, computadores e/ou videogames. Nesta comparação do ontem e do hoje e os espaços utilizados, os estudantes demonstraram os motivos de algumas mudanças nas seguintes falas:

\footnotetext{
Antigamente, brincava na rua, hoje é perigoso (Melhor do Baile).

Antigamente, não tinha tecnologia. Hoje brincamos de Free Fire (Rique).

Antigamente, eles faziam carrinho de rolemã, jogavam bolinha de gude e hoje não fazemos mais isso (El Gato).

Antigamente, brincava mais na rua porque não tinha tecnologia e nem perigo (Nini Chique).

Não podemos mais brincar na rua porque há bêbados dirigindo e ladrões (Cainão).
}

No estudo de Pereira (2015), a autora verificou que as brincadeiras da maioria das crianças pesquisadas ocorriam dentro das casas e poucas tinham possibilidade de brincar ao ar livre (nas ruas e até mesmo nas calçadas). Para Lira e Rubio (2014, p. 4), antigamente, " $[\ldots]$ as crianças tinham maior liberdade para brincar, mais espaço e mais tempo; nas ruas e praças as pessoas se encontravam para brincar, correr, jogar e aprender uns com os outros". As autoras ainda justificam essas alterações:

Percebemos que o ritmo de vida mudou, refletindo mudanças no modo de brincar da criança, as brincadeiras de rua quase não acontecem mais, a urbanização e a violência trouxeram uma nova caracterização das ruas, que já não são adequadas para a permanência das crianças (LIRA; RUBIO, 2014, p. 4).

Complementando o exposto, Kishimoto e Santos (2016) dissertam que: 
Hoje, a questão da violência é um assunto muito presente para ser analisado; tem relação com a questão da falta de espaços alternativos. Estão diminuindo cada vez mais os espaços de brincadeiras coletivas, onde as crianças de diferentes idades possam aprender as brincadeiras, pois ninguém nasce sabendo brincadeiras. Brincar é um fato social que se aprende. Alguém precisa ensinar. [...] Se hoje o espaço de brincar na rua está restrito, assim como os espaços públicos, então raramente as crianças brincam juntas fora da escola (p. 145).

Cotidianamente, os alunos se dividem entre os estudos com outras atividades. Ao questionarmos o que eles passam mais tempo fazendo, temos na tabela 2 :

Tabela 2:1 Atividades que os alunos passam mais tempo fazendo.

\begin{tabular}{l|c}
\hline Atividade escolhida & Quantidade \\
\hline Usar o celular & 17 \\
Brincar na rua ou em outro espaço & 10 \\
Assistir televisão & 06 \\
\hline
\end{tabular}

Fonte: Elaborada pelas autoras.

Como explicações de suas preferências, os estudantes nos trouxeram várias assertivas. Em relação ao uso do celular, os alunos afirmaram:

Fico jogando ou assistindo vídeo (Crucher Fox).

Porque é da hora jogar com outras pessoas que você não conhece (Negomate).

Eu fico falando com meus parentes de fora, amigos e, às vezes, fico jogando (Morena).

Porque eu fico conversando com minhas amigas, jogando, assistindo Youtube (Flor Negra).

Porque minhas amigas não tem tempo para brincar e é a única coisa que tem para fazer (Moreninha).

Analisando os excertos, podemos depreender que mesmo quando os estudantes utilizam estes aparelhos estão, de certa forma, jogando. Para Cairoli (2010), durante as brincadeiras na internet:

[...] a relação entre a criança e o processo de criação fica restrito às possibilidades oferecidas por determinado site, mesmo que estas possam ser inúmeras. Além disso, nas brincadeiras on-line, o corpo também está fora da atividade, já que para brincar on-line basta clicar no botão do mouse. Também podemos perceber que nesta atividade aparece um brincar com as imagens virtuais (p. 345).

Para o tempo dispendido na frente da televisão, Nini Chique alega: "Eu gosto de assistir a desenhos, séries etc.". Já Kevinho vai além do ato de assistir: "Meu irmão e eu gostamos porque dormimos rápido".

Um estudo feito por Rafihi-Ferreira (2015) aponta que assistir à TV antes de dormir era um hábito bem frequente nas crianças. Para a autora, ficar exposto ao televisor no momento de dormir pode interferir nos padrões do sono, pois pode deixar as crianças alertas e ativas ou interferir na qualidade do mesmo. 
Kishimoto e Santos (2016) afirmam que o brincar com jogos e brincadeiras, bem como a construção dos brinquedos de qualquer natureza, possibilita às crianças o desenvolvimento do imaginário, a socialização e a interação e é mais proveitoso do que as crianças permanecerem sentadas sozinhas em frente a um televisor.

\begin{abstract}
A Bola
O pai deu uma bola de presente ao filho. Lembrando o prazer que sentira ao ganhar a sua primeira bola do pai. Um número 5, sem tento oficial de couro. Agora não era mais de couro, era de plástico. Mas era uma bola. O garoto agradeceu, desembrulhou a bola e disse "Legal!". Ou o que os garotos dizem hoje em dia quando gostam do presente ou não querem magoar o velho. Depois começou a girar a bola, à procura de alguma coisa. - Como é que liga? - perguntou. - Como, como é que liga? Não se liga. O garoto procurou dentro do papel de embrulho. - Não tem manual de instrução? O pai começou a desanimar e a pensar que os tempos são outros. Que os tempos são decididamente outros. - Não precisa manual de instrução. - O que é que ela faz? - Ela não faz nada. Você é que faz coisas com ela. - O quê? Controla, chuta... - Ah, então é uma bola. - Claro que é uma bola. - Uma bola, bola. Uma bola mesmo. - Você pensou que fosse o quê? - Nada não. O garoto agradeceu, disse "legal" de novo, e dali a pouco o pai o encontrou na frente da tevê, com a bola nova do lado, manejando os controles de um videogame. Algo chamado "Monster Ball", em que times de monstrinhos disputavam a posse de uma bola em forma de bip eletrônico na tela ao mesmo tempo que tentavam se destruir mutuamente. $\mathrm{O}$ garoto era bom no jogo. Tinha coordenação e raciocínio rápido. Estava ganhando da máquina. $\mathrm{O}$ pai pegou a bola nova e ensaiou algumas embaixadas. Conseguiu equilibrar a bola no peito do pé, como antigamente, e chamou o garoto. - Filho, olha. $\mathrm{O}$ garoto disse "legal", mas não desviou os olhos da tela. O pai segurou a bola com as mãos e a cheirou, tentando recapturar mentalmente o cheiro de couro. A bola cheirava a nada. Talvez um manual de instrução fosse uma boa ideia, pensou. Mas em inglês, para a garotada se interessar (VERÍSSIMO, 2001, p. 41).
\end{abstract}

Em "A Bola", Veríssimo (2001) expõe uma realidade de vários contextos sociais, nos quais os jogos e as brincadeiras tradicionais estão sendo substituídos pela tecnologia e pelos jogos eletrônicos cada vez mais sofisticados. É indiscutível que as crianças devem ser respeitadas em seus interesses, gostos e modo de brincar, pois quando o jogo vira obrigação, ele perde seu caráter de espontaneidade e consequentemente deixa de ser jogo (CAMPOS, 2001).

O brincar na rua ou em outro espaço apresentou justificativas análogas. Para eles, brincar proporciona divertimento e o contato com colegas, como aparece na fala do Ruizinho: "Eu me divirto e passo o tempo com meus amigos".

Cardoso (2004) declara que "[...] todos os dias, é necessário brincar, mesmo que tenhamos prova, mesmo que faça chuva ou faça sol. Temos que pular, correr, fantasiar e criar, preparar a rua para mais um dia" (p. 87). A autora ainda complementa: "[...] de casa para a rua, da rua para a escola, da escola e na hora do recreio, quem conta um conto aumenta um ponto. Brinca-se de um jeito, joga-se de outro, mas as crianças continuam sentindo prazer no brincar" (CARDOSO, 2004, p. 125).

Elencamos na tabela a seguir o que eles gostam de fazer no tempo livre (frisando que os discentes poderiam citar mais de uma atividade):

Tabela 3:2 O que os discentes gostam de fazer no tempo livre.

\begin{tabular}{l|l}
\hline Atividade escolhida & Quantidade \\
\hline
\end{tabular}


Talila Schimith; Andresa de Souza Ugaya

\begin{tabular}{l|l}
\hline Jogar bola & 10 \\
Brincar & 10 \\
Celular & 09 \\
Assistir televisão & 08 \\
Free Fire & 06 \\
Videogame & 05 \\
Computador & 04 \\
Andar de bicicleta & 03 \\
Dormir & 02 \\
Youtube & 02 \\
Outros & 04 \\
\hline
\end{tabular}

Fonte: Elaborada pelas autoras.

Várias atividades apareceram quando os alunos foram questionados sobre o que gostavam de fazer no tempo livre. "Jogar bola" e "brincar" foram citados dez vezes cada uma. "Dormir" e "assistir ao Youtube" foram os menos recorrentes (dois de cada). Para o item "outros" temos: soltar pipa, ajudar a mãe, ajudar os avós e ler livro. Se somarmos as atividades que fazem uso da tecnologia (celular, assistir à televisão, videogame, computador e Youtube) totalizamos vinte e cinco. Já as atividades que envolvem o brincar (jogar bola, brincar, soltar pipa e andar de bicicleta) totalizam vinte e quatro. Assim, por mais que o uso da tecnologia impere no cotidiano, o brincar ainda aparece como uma prática das crianças.

No estudo realizado por Cunha (2007), a autora conclui que nenhuma criança troca algo que está presente na tecnologia midiática por seus pares que brincam tão próximos. Para ela:

\begin{abstract}
A criança brinca com elementos da mídia como sempre brincou com os demais elementos culturais: brinca com símbolos, valores, imita o cotidiano, coloca emoções nele, conhece sua cultura sempre com um único objetivo: diversão. Manter a diversão, buscá-la, é o que a criança se esforça para fazer, deste modo, ela usa elementos de seleção antes de seus jogos para manter os times "equilibrados" e assim garantir o fator surpresa neles; para se divertir usa o diálogo, a comunicação e prova para nós: brincar, com pião de cabaça ou beyblade, será sempre algo da especialidade delas. Brincar de luta, de trocar figurinhas ou roupas de bonecas, de girar ao corpo ou alguma coisa... são velhos suportes lúdicos com nomes que mudam com a mídia. Observamos assim, que com grande mídia ou não, com televisão ou não, os velhos jogos estarão sempre onde estiverem grupos infantis (CUNHA, 2007, p. 7).
\end{abstract}

Ao comparar os jogos e as brincadeiras que os adultos escolhidos mais gostavam quando crianças com os jogos e as brincadeiras que os estudantes brincam nos dias de hoje, podemos verificar que muitos aparecem em ambos os grupos:

Tabela 4: Brincadeiras preferidas dos responsáveis quando crianças e dos alunos.

\begin{tabular}{l|l|l|l}
\hline \multicolumn{2}{c|}{ Responsáveis } & \multicolumn{2}{c}{ Alunos } \\
\hline Esconde-esconde & 18 & Pega-pega & 26 \\
Bola & 11 & Esconde-esconde & 22
\end{tabular}




\begin{tabular}{l|l|l|l} 
Pular corda & 10 & Jogar bola & 22 \\
Queimada & 10 & Pular corda & 4 \\
Pega-pega & 9 & Amarelinha & 4 \\
Amarelinha & 8 & Jogos eletrônicos & 4 \\
Betis/taco & 7 & Cabra cega & 4 \\
Boneca & 3 & 3 \\
Passa anel & 3 & 3 \\
Pega ladrão & 2 \\
Elástico & 2 \\
Bolinha de gude & 2 \\
Estrela nova cela & 2 \\
Pique salve & 2 \\
Estátua & 2 \\
Mamãe da rua & 15
\end{tabular}

Fonte: Elaborada pelas autoras.

Por "outros" respondido pelos responsáveis, surgiram a "cabra cega", "mãe da sopa", "dama", “dominó", "carrinho", "escravos de Jó", "dança da carrapeta", "pião", "pipa", "3 cortes", "casinha", "pique 12 3", "stop", "7 cacos" e "salada mista". Já as respostas dos alunos foram "dama", "carrinho", "skate", "alto chão", "gato mia", "jogo de carta (UNO)", "pega-pega da corrente", "bicicleta”, "boneca", "escolinha", "verdade ou desafio", "pipa" e "banco imobiliário".

Ao compararmos ambos, percebemos que algumas brincadeiras são praticamente as mesmas, embora as gerações sejam diferentes. A brincadeira "pega ladrão" citada pelos responsáveis aparece com o nome de "polícia e ladrão" para os estudantes.

Carvalho et al. (2003) discorrem que as brincadeiras das crianças são contextualizadas sócio-culturalmente, isto é, elas não podem apenas estar relacionadas com o ambiente na sua forma de espaço físico, mas, além disso, a relação é determinada com o social e o cultural.

Dentre as brincadeiras citadas, a "pega-pega" aparece com diversas variações: "pega-pega", "pega ladrão", "polícia e ladrão", "pique salve", "pique 1, 2, 3", "alto chão" e "pega-pega da corrente".

O que se esconde sob esses nomes diversificados é, ao mesmo tempo, a universalidade e a especificidade da brincadeira enquanto prática cultural. Brincadeiras são como rituais que se transmite, repetidos ou recriados, em ambientes socioculturais distintos (CARVALHO et al., 2003, p. 15).

Das práticas citadas, alguns jogos e brincadeiras eram encontrados mais facilmente na época que os escolhidos eram crianças: "mãe da sopa", "mãe da rua", "escravos de Jó", "dança da carrapeta" e "salada mista". Atualmente, algumas práticas são mais comuns devido à criação de novos jogos e brincadeiras e/ou pela facilidade de adquirir alguns objetos necessários para algumas vivências como skate, UNO, pega-pega da corrente, verdade ou desafio e banco imobiliário.

Para Kishimoto e Santos (2016): 
[...] à primeira vista, em nosso mundo moderno e tecnológico, transbordante de informação e estímulo, os brinquedos e as formas de brincar mudaram muito. Isso é parcialmente verdadeiro, especialmente quando se focalizam crianças urbanas de classe média e alta. Nesses segmentos, muitos jogos tradicionais deixaram de ser praticados. É raro um menino paulistano de classe média nascido a partir da década de 1970 que saiba empinar pipa e muito mais raro um que saiba construí-la; da mesma forma, é rara a menina do mesmo segmento social que tenha aprendido, por exemplo, algumas das diversas versões de rimas que acompanham o jogo de bola tradicional conhecido como "Ordem", Quietas" ou "Bola na parede", no qual as ordens verbais são acompanhadas por movimentos correspondentes da criança enquanto joga a bola contra uma parede, sem deixá-la cair no chão (p. 19).

As transformações que ocorrem ao longo do tempo são inevitáveis, o primordial é que as crianças nunca parem de brincar e jogar, pois é através destas manifestações culturais que elas conhecem o mundo a sua volta e interagem com ele.

Para Cardoso (2004), o importante sempre é "[...] lembrar, brincar, imaginar, criar e sorrir" (p. 117). A autora ainda complementa que esses momentos de vidas devem ser bem aproveitados para que se eternizem e futuramente virem lembranças em nossas memórias.

\section{CONSIDERAÇÕES FINAIS}

$\mathrm{O}$ retorno que os alunos e os familiares participantes dispensaram durante o percurso foi imprescindível. Sem a participação ativa deles, não seria possível o levantamento de tantos dados relevantes para a análise.

Logo, podemos inferir que a pesquisa nos evidenciou algumas mudanças pertinentes aos jogos e brincadeiras em relação às gerações, bem como os espaços que as crianças utilizam para brincar. Se antes as ruas eram tomadas por jogos e brincadeiras tradicionais, atualmente estas acontecem, comumente, dentro da própria casa e conta, na maioria das vezes, com a utilização de celulares, computadores e/ou videogames. $\mathrm{O}$ primordial é que a criança ainda continua brincando, de alguma maneira, seja na rua, no quintal de casa, no quarto, entre outros lugares, tradicionalmente ou através de jogos eletrônicos.

Assim sendo, as escolas e os professores têm a incumbência de proporcionar vivências contextualizadas, ou seja, fazer uma investigação e conhecer a origem do seu alunado e a diversidade cultural presente em suas aulas para que o trabalho pedagógico esteja pautado nas diferenças existentes, bem como envolver a família nesse processo, para que assim os alunos se sintam instigados a aprender de fato e a participar ativamente da construção do seu conhecimento.

\section{REFERÊNCIAS}

ARIÉS, P. História social da criança e da família. 2. ed. Rio de Janeiro: Guanabara, 1986.

BORDENAVE, J. E. D. O que é participação. 8. ed. São Paulo: Brasiliense, 1994.

BRASIL. Livro de estudo: módulo II. Brasília: MEC/SEB/Seed, 2005. (Coleção PROINFANTIL; Unidade 7).

BROUGÈRE, G. Brinquedo e cultura. 8. ed. São Paulo: Cortez, 2010. 
CAIROLI, P. A criança e o brincar na contemporaneidade. Revista de Psicologia da IMED, v. 2, n. 1, p. 340-348, 2010.

CAMPOS, M. C. R. M. A importância do jogo na aprendizagem. São Paulo: USP, 2001.

CARDOSO, S. R. Memória e jogos tradicionais infantis: lembrar e brincar é só começar. Londrina: Eduel, 2004.

CARvalho, A. M. A.; MAGAlhães, C. M. C.; PONTES, F. A. R.; BICHARA, I. D. (org.). Brincadeira e cultura: viajando pelo Brasil que brinca. São Paulo: Casa do Psicólogo, 2003.

CHICON, J. F.; SÁ, M. G. C.; FONTES, A. S. Natação, ludicidade e mediação: a inclusão da criança autista na aula. Revista da Sobama, v. 15, n. 1, p. 15-20, jan./jun. 2014.

COSTA, A. M.; SOUSA, S. B. Educação física e esporte adaptado: história, avanços e retrocessos em relação aos princípios da integração/inclusão e perspectivas para o século XXI. Revista Brasileira de Ciências do Esporte, v. 25, n. 3, p. 7-160, maio 2004.

CUNHA, C. T. Mídia e criança: a permanência dos jogos tradicionais. In: CONGRESSO BRASILEIRO DE CIÊNCIAS DO ESPORTE, 15., 2007, Recife. Anais [...]. Recife: Colégio Brasileiro de Ciências do Esporte - CBCE, v. 7, 2007. p.1-8.

DEL-MASSO, M. C. S.; COTTA, M. A. C.; SANTOS, M. A. P. Instrumentos e técnicas de pesquisa. São Paulo: AVA Moodle Unesp [Edutec], 2018.

DOXSEY, J. R.; DE RIZ, J. Metodologia da pesquisa científica. Vila Velha: ESAB, 2003. (Apostila).

GOMES, R. A análise de dados em pesquisa qualitativa. In: MINAYO, M. C. S. (org.). Pesquisa social: teoria, método e criatividade. 26. ed. Petrópolis: Vozes, 2007. p. 79-108.

GONSALVES, E. P. Iniciação à pesquisa científica. Campinas: Editora Alínea, 2001.

GUIMARÃES, A. A.; PELlini, F. C.; ARAUJO, J. S. R.; MAZZINI, J. M. Educação física escolar: atitudes e valores. Motriz, v. 7, n. 1, p. 17-22, jan./jun. 2001.

HIRSH-PASEK, K. Einstein teve tempo para brincar: como nossos filhos realmente aprendem e por que eles precisam brincar. Rio de Janeiro: Guarda-Chuva, 2006.

KISHIMOTO, T. M. (org.). Jogo, brinquedo, brincadeira e a educação. 14. ed. São Paulo: Cortez, 2011.

KISHIMOTO, T. M. (org.). O brincar e suas teorias. São Paulo: Cencage Learning, 1998.

KISHIMOTO, T. M. O brinquedo na educação: considerações históricas. In: SÃO PAULO. O cotidiano da pré-escola. São Paulo: FDE, 1995. p. 39-45. (Série Ideias, n. 7). Disponível em: http://www.crmariocovas.sp.gov.br/pdf/ideias_07_p039-045_c.pdf. Acesso em: 20 jun. 2020.

KISHIMOTO, T. M. Jogos infantis: o jogo, a criança e a educação. 6. ed. Petrópolis: Vozes, 1993.

KISHIMOTO, T. M.; SANTOS, M. W. (org.). Jogos e brincadeiras: tempos, espaços e diversidade. São Paulo: Cortez, 2016.

LEITE, A. M.; MEDEIROS, M. L. Brincar na escola: caminhos e escolhas. Cadernos Cenpec, v. 4, n. 1, p. 142-163, jun. 2014.

LIRA, N. A. B.; RUBIO, J. A. S. A Importância do brincar na educação infantil. Revista Eletrônica Saberes da Educação, v. 5, n. 1, p. 1-22, 2014.

MINAYO, M. C. S. O desafio do conhecimento: pesquisa qualitativa em saúde. 14. ed. São Paulo: HUCITEC, 2014. 
PEREIRA, J. M. Percepções das crianças, familiares e professores sobre as brincadeiras tradicionais de rua no espaço escolar, como recurso para o desenvolvimento infantil na pré-escola. 2015 . $52 \mathrm{f}$. Monografia (Licenciatura em Educação Física) - Curso de Educação Física - Licenciatura, Universidade Regional do Noroeste do Estado do Rio Grande do Sul, Unijuí - Campus Santa Rosa, 2015.

POLETTO, R. C. A ludicidade da criança e sua relação com o contexto familiar. Revista Psicologia em Estudo, v. 10, n. 1, p. 67-75, jan./abr. 2005.

PONTES, F. A. R.; MAGALHÃES, C. M. C. A transmissão da cultura da brincadeira: algumas possibilidades de investigação. Psicologia: Reflexão e Crítica, v. 16, n. 1, p. 117-124, 2003.

RAFIHI-FERREIRA, R. Intervenção comportamental para problemas de sono na infância. 2015. 175 f. Tese (Doutorado em Psicologia) - Instituto de Psicologia, Universidade de São Paulo, São Paulo, 2015.

SANTOS, T. R. L. Um resgate das brincadeiras de infância: o ensinar a brincar entre pais e filhos. ÁGORA Revista Eletrônica, v. 9, n. 17, p. 76-86, dez. 2013.

SOUZA, A. S.; LEITÃO, A.; PRODÓCIMO, E. Práticas educativas de professores de educação física do ensino fundamental e sua relação com a teoria dos estilos parentais. Conexões, v. 14, n. 1, p. 66-86, jan./mar. 2016.

VAGO, T. M. Pensar a educação física na escola: para uma formação cultural da infância e juventude. Cadernos de Formação RBCE, v. 1, n. 1, p. 25-42, set. 2009.

VERÍSSIMO, L. F. Comédias para se ler na escola. Rio de Janeiro: Objetiva, 2001.

VOLPATO, G. Jogos, brincadeira e brinquedo: usos e significados no contexto escolar e familiar. Florianópolis: Cidade Futura, 2002.

WINNICOTT, D. W. O brincar e a realidade. Rio de Janeiro: Imago, 1975.

ZAMBERLAN, M. A. T.; BIASOLI-ALVES, Z. M. M. Interações familiares: teoria, pesquisa e subsídios à intervenção. Londrina: UEL, 1997.

Recebido em: 22 jun. 2020.

Aprovado em: 26 out. 2020. 